\title{
Bamboo Fibre-reinforced Semi-Metallic Brake Friction Materials for Automotive Applications
}

\author{
R. J. Talib ${ }^{1,2, a}$, K. Ramlan ${ }^{3}$, N. I. Ismail ${ }^{1,2}$, M. F. Ismail ${ }^{1,2}$ and A. O. Eliasidi ${ }^{4}$ \\ ${ }^{1}$ Faculty of Mechanical Engineering, Universiti Teknologi MARA Pulau Pinang, 13500 Permatang Pauh, Malaysia \\ ${ }^{2}$ ARTeC, Universiti Teknologi MARA Pulau Pinang, 13500 Permatang Pauh, Penang, Malayisa \\ ${ }^{3}$ Faculty of Mechanical Engineering, University Technology MARA, 40450 Shah Alam, Malaysia \\ ${ }^{4}$ Advanced Materials Centre, SIRIM Berhad, Jalan High-Tech 2/3, Kulim Hi-Tech Park, 09000 Kulim, Malaysia
}

\begin{abstract}
Three friction material formulations composed of bamboo fiber along with binder, friction modifiers and filler have been prepared through powder metallurgy process. Sample F1 and F2 are composed of $10 \mathrm{wt}$ \% of copper and barium, respectively, while the other ingredients in both formulations have the same wt. \%. The wt. \% of bamboo fiber in sample F3 is, however, increased by $100 \%$, while the compositions of the other ingredients are proportionally decreased. The samples were examined for their porosity, hardness, and friction and wear properties using hot bath, Rockwell hardness tester, and CHASE friction dynamometer, respectively. The test results are compared with those of a commercial sample as the benchmark. Normal and hot frictions of all the three samples developed comply with the requirements specified by Automotive Manufacturer Equipment Companies Agency (AMECA). However, sample F3 which is composed of 20 wt. \% of bamboo fiber does not comply with the minimum requirement of friction coefficient. Whereas, sample F2, which is composed of $10 \mathrm{wt}$ \% of bamboo fiber and $10 \mathrm{wt}$. \% of barium, has lower friction coefficient than the commercial sample, and has a sudden drop in friction coefficient at a temperature of $500^{\circ} \mathrm{F}$. Out of three developed samples, sample F1, which is composed of $10 \mathrm{wt}$. \% of bamboo fiber and 10 wt. \% of copper, complies with all the requirements and has higher friction coefficient than the commercial sample, and has higher fade resistance. Thus, it could be postulated that bamboo fiber could be used as a reinforcing fiber with composition of $10 \mathrm{wt} . \%$.
\end{abstract}

\section{Introduction}

Friction materials are a heterogeneous material and are composed four components, namely; (i) the reinforcing fibres, (ii) binders, (iii) fillers, and (iv) frictional additives. Reinforcing fiber is use to provide the necessary mechanical strength, rigidity, integrity, and thermal stability at high temperatures. The selection of ingredients and weight percentages used in the friction formulation will significantly affect the friction and wear characteristics, braking performance, and friction-induced noise $[1,2]$. In the braking process, kinetic energy of a moving vehicle is converted into thermal energy. The heat generated is dissipated to the surroundings through the mechanism of convection, conduction, and radiation. The ability of brake disc to dissipate this heat significantly affects the performance and wear life of the friction materials.

The phenolic resin had the strongest influence on tribological behaviours on the semi-metallic brake friction materials [3]. There is no simple correlation between friction values and wear rates with mechanical, chemical and thermal properties of the friction materials [4, 5]. In the process of developing a new formulation, the researchers should compromise some of the properties in order to

\footnotetext{
${ }^{\mathrm{a}}$ Corresponding author : drtalib@ppinang.uitm.edu.my
} 
get the best formulation. The main criterion for acceptance of a new formulation is based on the results of performance test rather than the mechanical test [6]. The mechanical properties are test is used to control the quality of the formulations that has been developed. The effect of bamboo fiber weight percentage in the semi-metallic brake material formulation on the mechanical and tribological characteristics will be the main focus in this study.

\section{Experimental}

Three friction material formulations composed of bamboo fiber along with binder, friction modifiers and filler have been prepared through powder metallurgy process. The powders were mixed for 10 minutes in tabular mixer and then warm compacted under a pressure of $150 \mathrm{~kg} / \mathrm{cm}^{2}$ at a temperature of $190^{\circ} \mathrm{C}$ with holding time of 3 minutes. The samples were compacted in a assmebly die with a sample dimension of $25 \mathrm{~mm} \times 25 \mathrm{~mm} \times 7 \mathrm{~mm}$. Post curing was carried out in an oven at a temperature of $180^{\circ} \mathrm{C}$ for 3 hours. Sample F1 and F2 are composed of 10 wt. \% of copper and 10 wt. $\%$ of barium, respectively, while the other ingredients in both formulations have the same wt. $\%$. The wt. \% of bamboo fiber in sample F3 is, however, increased by $100 \%$, while the compositions of the other ingredients are proportionally decreased and composed both copper and barium having the same wt. \%. Table 1 shows the composition for each formulation. Sample COM is a commercially available semi-metallic brake pad is used as a benchmark. Each sample was subjected to porosity, hardness, and friction tests. Table 2 lists the test equipment and test procedures employed in this work.

Table 1. Ingredients in the formulation

\begin{tabular}{|c|c|c|c|}
\hline Ingredients & FC (\%) & FB $(\%)$ & FBC (\%) \\
\hline Bamboo & 10 & 10 & 20 \\
\hline Resin & 15 & 15 & 13.3 \\
\hline Graphite & 15 & 15 & 13.3 \\
\hline Steelwool & 25 & 25 & 22.2 \\
\hline Iron Oxide & 25 & 25 & 22.2 \\
\hline Copper & 10 & 0 & 4.4 \\
\hline Barium & 0 & 10 & 4.4 \\
\hline Total & 100 & 100 & 100 \\
\hline
\end{tabular}

Table 2. List of equipment and standards

\begin{tabular}{|l|l|l|}
\hline \multicolumn{1}{|c|}{ Test procedures } & Equipment & \multicolumn{1}{c|}{ Standard } \\
\hline Porosity & Hotbath & JIS D 4418 1996 [7] \\
\hline Rockwell hardness & Rockwell hardness tester & MS 474. Part 2. 2003 [8] \\
\hline jFriction and wear test & CHASE dynamometer & SAE J661 Feb 1997 [9] \\
\hline
\end{tabular}

Friction coefficient and wear were results were obtained using Link Model 600 CHASE machine. The test procedure using CHASE machine is described in Society of Automotive Engineer standard SAE J661 Feb 1997 [9]. In this test, the sample was pressed against a rotating brake drum with a constant rotating speed of $417 \mathrm{rpm}$ under the load of $647 \mathrm{~N}$ and subjected to test program. Briefly, each sample was subjected to seven test runs with the following sequences; (i) baseline, (ii) first fade, (iii) first recovery, (iv) wear, (v) second fade, (vi) second recovery, and (viii) baseline rerun. The samples thickness were measured and weighed before and after testing.

Society of Automotive Engineer defined the normal friction coefficient as average of the four readings taken at $200,250,300$ and $400^{\circ} \mathrm{F}$ on the second fade curve [10]. The hot friction coefficient is defined as the average of the ten readings taken at 400 and $300^{\circ} \mathrm{F}$ on the first recovery; 450,500 , 550,600 and $650^{\circ} \mathrm{F}$ of the second fade; and 500,400 and $300^{\circ} \mathrm{F}$ of the second recovery run. 
Automotive Manufacturer Equipment Companies Agency, USA has set the friction coefficient requirements as follow [11]; (a) shall have normal friction coefficient of 0.25 and higher or a hot of 0.15 and above, (b) shall have friction coefficient above 0.15 between 200 and $550{ }^{\mathrm{O}} \mathrm{F}$ inclusive in second fade, or between 300 and $200{ }^{\circ} \mathrm{F}$ during the secondary fade.

\section{Results and Discussions}

\subsection{Mechanical Properties}

Table 3 shows the mechanical and tribological test results while Figure 1 shows the effect of material compositions on the porosity and hardness properties of the sample. It was observed that there is no simple correlation between the material compositions with the mechanical properties of semi-metallic brake friction materials as shown in Table 3 and Figure 1 and Figure 2. Sample COM has the lowest porosity and the highest hardness. Sample FB which composed of barium has the lowest porosity among the three developed sample and supposed to have higher hardness. Sample FBC which composed of higher bamboo fibre wt. percentage has the highest hardness even though having higher porosity than sample FB. The friction materials are heterogeneous materials, thus the mechanical and tribological properties cannot be predicted [1]. Thus, each formulation develop need to be tested in the lab as well on the road before it could be allowed to be used on the road.

Table 3. Test results

\begin{tabular}{|c|c|c|c|c|c|}
\hline Sample & $\begin{array}{c}\text { Porosity } \\
(\%)\end{array}$ & $\begin{array}{c}\text { Rockwell } \\
\text { hardness } \\
\left(\mathbf{H R}_{\mathbf{S}}\right)\end{array}$ & $\begin{array}{c}\text { Normal } \\
\text { friction }\end{array}$ & $\begin{array}{c}\text { Hot } \\
\text { Friction }\end{array}$ & $\begin{array}{c}\text { Thickness } \\
\text { loss (\%) }\end{array}$ \\
\hline COM & 14.88 & 82.4 & 0.38 & 0.33 & 0.56 \\
\hline FC & 24.78 & 56.8 & 0.41 & 0.38 & 2.8 \\
\hline FB & 20.98 & 45.6 & 0.32 & 0.27 & 0.91 \\
\hline FBC & 23.79 & 78.7 & 0.36 & 0.29 & 2.7 \\
\hline
\end{tabular}

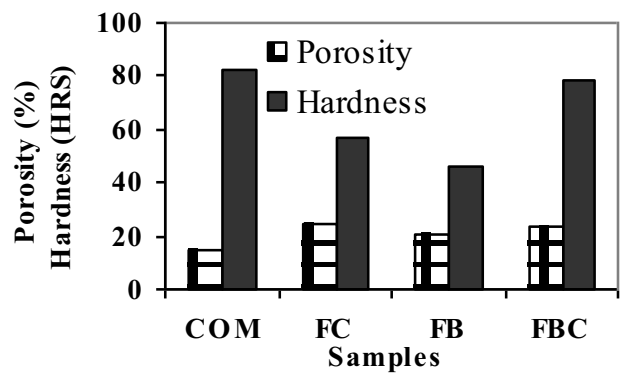

Figure 1. Porosity and Hardness Vs material composition

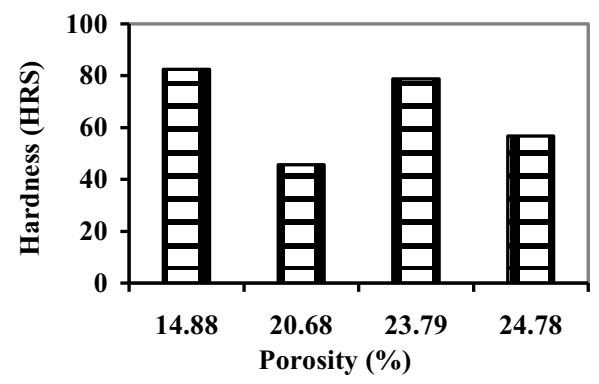

Figure 2. Hardness Vs porosity

\subsection{Friction Coefficient}

Normal and hot frictions of all the three samples developed comply with the requirements specified by AMECA (Table 3). However, sample FBC does not comply with the minimum requirement of friction coefficient which less than 0.15 in second fade test condition as shown in Figure 3. This phenomenon could be due to higher wt. percentage of bamboo fibre in the composition. Second fade run generated higher temperature during braking which will elucidate the brake fade of the sample being tested. Based on test results, it could be postulated that $10 \%$ wt. percentage of bamboo fibre is the optimum wt. percentage in the composition. Whereas, sample FB has lower friction coeffient than the 
commercial sample, and has a sudden drop of friction coeffient at a temperature of $500^{\circ} \mathrm{F}$. Sample FC complies with all the requirements and has higher friction coeffient than the commercial sample, more stable friction coefficient, has higher fade resistance and therefore could be seen as the optimized material composition under this work. The addition copper in the composition has improved the frcition coefficient due to higher heat transfer during braking process. Based on the mechanical and friction test results, it could be concluded that the decision of the best formulation can be selected based on the fricton test results rather than the mechanical test results.

Figure 4 shows the friction coefficient characteristics during second recovery cycle. The first fade characteristic is not discussed because the temperature generated during this braking operation is below $288^{\circ} \mathrm{C}$ which is below the decomposition temperatures. It can be seen from Figure 3 that all samples developed almost recover to their respective base line friction coefficient readings when the brake drum and the sample are cooled to room temperature.

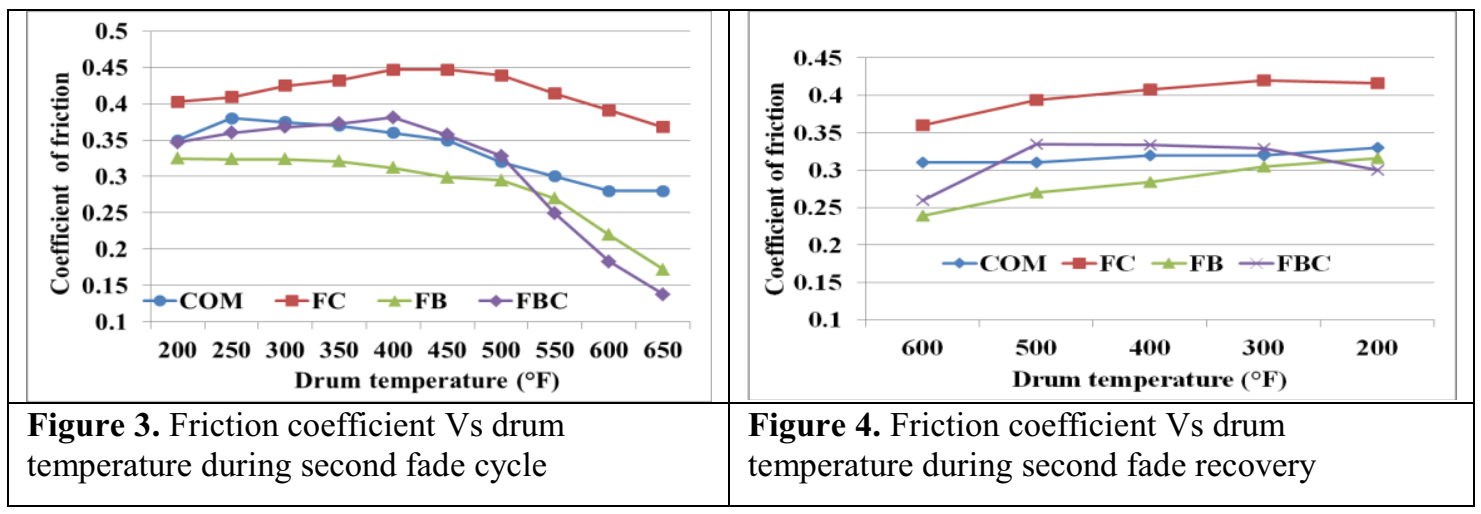

Figure 5 shows the effect of porosity and hardness on hot friction coefficient and thickness loss of the developed samples. For homogeneous materials, the lower the porosity and the higher the hardness, the higher will be friction coefficient. However, for friction materials this phenomena does not apply. Sample FC is the highest hot friction coefficent evenhough it porosity and hardness is not the highest among the developed samples (Figure 5(a), Table 3). Thus, it could be concluded that the physical and mechanical properties of friction materials are not simply correlated with hot friction properties. The physcial and mechanical properties of friction are use for quality control in manufacturing friction materials that using the same formulation.

(a)

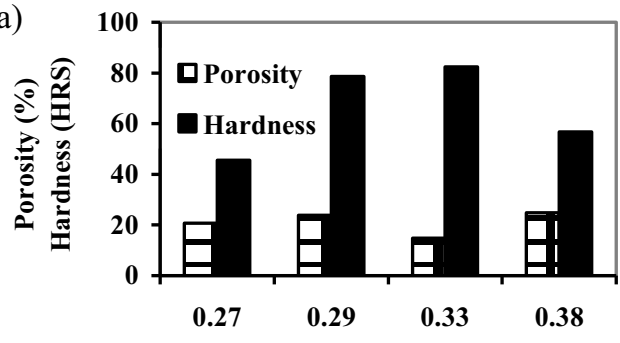

(b)

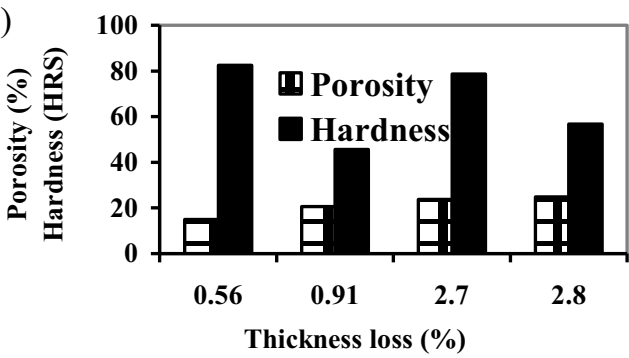

Figure 5. Effect of porosity and hardness on, (a) hot friction coefficient, and (b) thickness losss

\subsection{Wear}

The lowest thickness loss was observed for sample FB which composed 10\% wt percentage of Barium (Table 3). Addition of Barium has improved the wear resistance of the developed friction material 
even though has the lowest hardness. It can be seen in Figure 5(b) that there is no simple correlation between hardness with thickness loss. However, it was also noticed that the thickness loss increased with increasing porosity. Higher porosity indicates higher pore content in the formulation which result in less contact area, subsequently increased the thickness loss.

\subsection{Wear Mechanism}

It can be seen in Figure 6 that the harder peak asperities on the brake disc ploughed into the friction material surface during braking process. This process was a manifestation of abrasion wear mechanism. On the other hand, Figure 7 shows the symptom of adhesion wear mechanism. Figure 7(a) shows the formation of transfer patches while Figure 7(b) shows the formation of transfer layer where the transfer patches and wear fragment have been flattened, compacted and smeared on the worn surface. Thus, it could be postulated that both the abrasion and adhesion wear mechanisms are in operating during braking process.
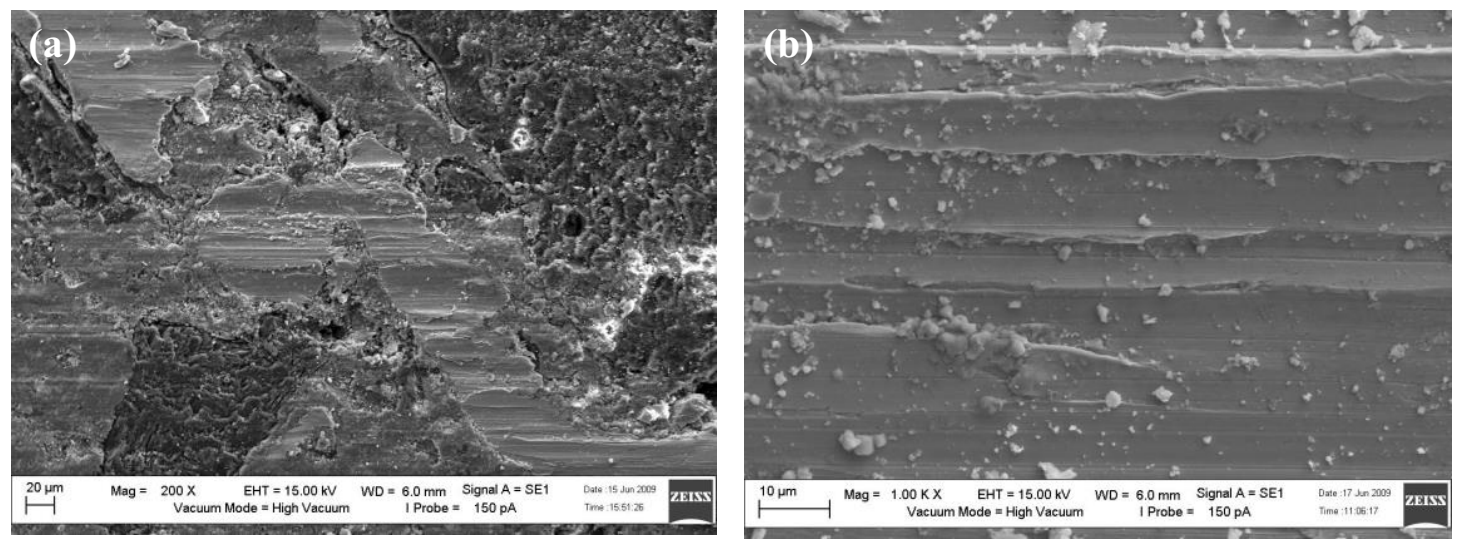

Figure 6. Abrasion wear mechanism; (a) harder peak asperities ploughed on the sample surface, (b) close-up view
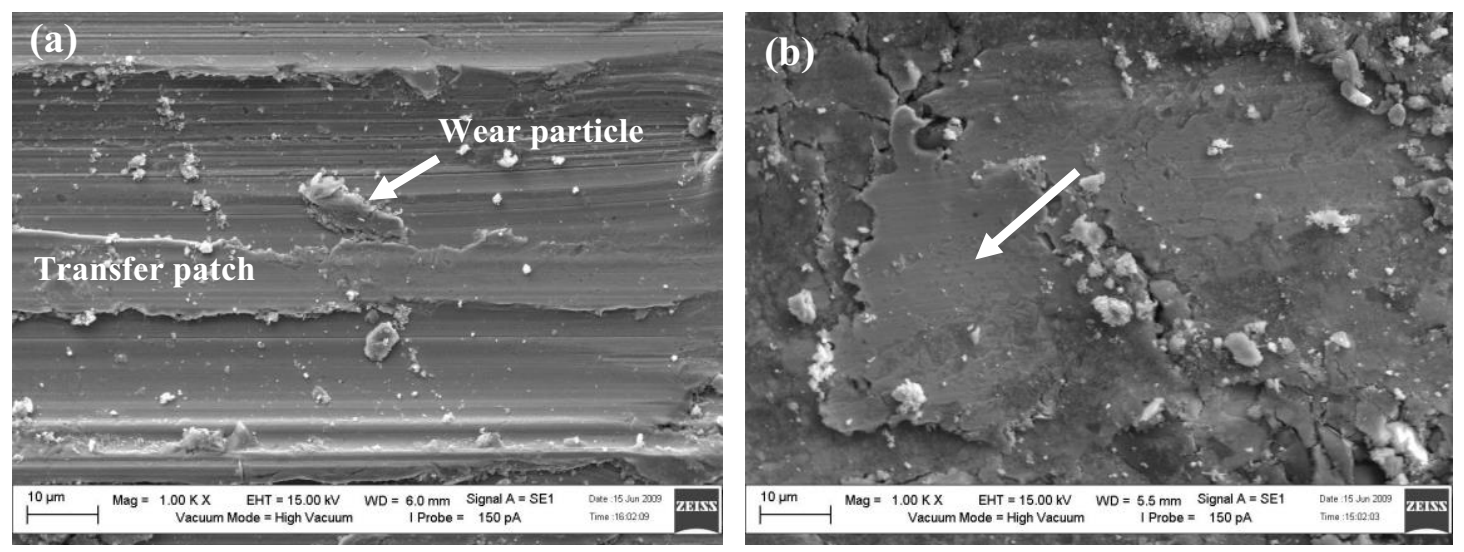

Figure 7. Adhesion wear mechanism; (a) formation of transfer patches, (b) formation of transfer layer and wear fragment to be detached

\section{Conclusions}

Three newly developed brake friction material with different bamboo fiber compositions have been successfully developed using powder metallurgy process. The samples had been subjected to 
mechanical and CHASE dynamometer friction tests. Based on test results obtained, the following phenomena could be postulated as follows; (i) the bamboo fiber could be used as a reinforcing fiber with composition of $10 \mathrm{wt}$. \% and $10 \mathrm{wt} . \%$ of Copper (ii) there are no simple correlations between the material composition with mechanical properties with tribological characteristics, (ii) there are no simple correlations between the mechanical properties with tribological characteristics, (iii) CHASE dynamometer friction results could be used in screening the formulations, and (iv) addition of copper improve COF due higher heat transfer during friction test while addition of barium improve the thickness loss.

\section{Acknowledgements}

This research was supported by Ministry of Science, Technology and Innovation, Malaysia with sciencefund grant No. 06-01-01-SF0809 and Univertsiti Teknologi MARA. The authors are grateful to SIRIM Berhad for providing research facilities.

\section{References}

1. M. Y. Cho, S. J Kim, D. Kim, H. Jang, (2005). Wear 258, 1682-1687

2. Ling Han, Li Huang, Jinsheng Zhang, Yafei Lu, (2006). Composites Science and Technology 66, 2895-2906

3. A. M. Zaharudin, M. N. Berhan, and R. J. Talib. (2011). American Institute of Physics Conf. Proc. 1400,274

4. K. Tanaka, S. Ueda, \& N. Noguchi, (1973). Wear 23: 349-365

5. S. M. Hsu, M. C. Shen, A. W. Ruff, (1997). Tribology International 30, 377

6. Talib Ria Jaafar, Mohmad Soib Selamat, Ramlan Kasiran, (2012). Selection of Best Formulation for Semi-metallic Brake Pads Development in Powder Metallurgy, In Katsuyoshi Kondoh (ed), Powder Metallurgy, INTEC Crotia, 1-30

7. JIS D 4418 (1996), Japanese Industrial Standard. "Test procedure of porosity for brake linings and pads of automobiles",

8. MS 474. Part 2 (2003), Malaysia Standarad. "Methods of Test for Automotive Friction materials (Brake Linings, Disc Pads and Bonded Shoe): Rockwell Hardness Test" (First Revision),

9. SAE J866 (Jan 96), Friction coefficient identification system for brake lining, Society of American Engineers, Warrendale, USA

10. SAE J661 (Feb 97), Brake lining quality test procedure, Society of American Engineers, Warrendale, USA

11. Vehicle equipment safety commission Regulation V3, minimum requirements and uniform test procedures for motor vehicle brake lining. Automotive Manufacturer Equipment Companies Agency Virginia, USA 